\title{
ESTUDIO CINETICO DE AMPICILINA EN EQUINOS
}

\author{
Lázaro Zurich Z. (MV), María T. Calderón G. (MV), \\ Herman Yaikin M. (MV)
}

Laboratorios de Farmacología y Microbiología. Facultad de Ciencias Veterinarias. Universidad de Chile. Casilla 2, Correo 15. Santiago, Chile.

\section{KINETIC OF AMPICILLIN IN EQUINES}

Kinetic of sodium ampicillin, 10 and $20 \mathrm{mg} / \mathrm{kg}$ of body weight were determined after intravenous administration to healthy race and thoroughbred horses. Seric concentrations of ampicillin were determined by microbiologic methods in 11 samples collected from cero to $\mathbf{4 8 0}$ minutes after dosing.

The plasma concentration-time curve showed a fast distribution (alpha) and a slower elimination phase (beta). It was found that a 2-compartment open-model system best described the disposition of ampicillin in the horse. Peripheric or "tissue" distribution volume was larger than the distribution volumen found in the central or "blood" compartment. These facts are related with the rate of the transference constants $k_{12}$ and $k_{21}$. It may be concluded that the high concentration of ampicillin in peripheric tissues can be of interest in extravascular infections in equines.

La ampicilina es un antibiótico de estructura betalactámica con reconocida efícacia sobre numerosas bacterias gram positivas y negativas y con amplio margen de seguridad. Estas razones han incrementado sus aplicaciones en las patologías infecciosas de diferentes especies y, muy especialmente, en el equino (Zurich y Villalobos, 1979; Tobin, 1981; Booth y MacDonald, 1982; Brander y Pugh, 1982).

Existe, sin embargo, escasa información sobre el comportamiento farmacocinético de este antibiótico en el caballo. Dürr (1976) utilizó ampicilina en dosis de $40 \mathrm{mg} / \mathrm{kg}$ por vía venosa y. obtuvo parámetros de distribución y eliminación, estableciendo la rapidez de ambos procesos a través de los valores de vida media plasmática, pero sin caracterizar un modelo de compartimentos que permita conocer en forma cuantitativa la transferencia de ampicilina desde la sangre hacia los tejidos y viceversa, con el fin de entregar la información que el clínico requiere para la formulación de esquemas terapéuticos eficaces. Estos estudios han sido realizados en otras especies (Mercer y Cols., 1977; Galtier y Charpeneau, 1979; Zurich y Cols., 1984) y han facilitado la adopción de modelos cinéticos compartimentales entregando información referente a la magnitud de los volúmenes de distribución que se alcanzan en los compartimentos central -sangre y órganos de gran perfusión - y periférico- tejidos de menor irrigación - como asimismo otros parámetros que contribuyen al conocimiento cinético integral de un fármaco (Ritschel, 1980; Cid, 1982).

En el presente trabajo se estudia la disposición de ampicilina en equinos a través de parámetros farmacocinéticos derivados de las curvas de concentraciones sanguíneas del antibiótico después de la administración intravenosa de dosis simples de 10 y $20 \mathrm{mg} / \mathrm{kg}$ a equinos clínicamente sanos.

\section{MATERIAL Y METODOS}

Los experimentos se realizaron en equinos mestizos y F.S. de Carrera clínicamente sanos y sin antecedentes de medicación previa con antibióticos y sometidos a condiciones similares de mantención y alimentación. El peso y edad promedio fue de $350 \mathrm{~kg}$ y 8,3 años respectivamente.

Trabajo financiado por Proyecto A. 1786-83 DIB, Universidad de Chile. 
El grupo 1, integrado por 12 caballos, recibió una dosis simple de $10 \mathrm{mg} / \mathrm{kg}$ de ampicilina sódica $\left({ }^{*}\right)$ por vía venosa en la vena yugular. A cada animal se le extrajo un total de 11 muestras de $8 \mathrm{ml}$ de sangre en tiempos 0 (Control), 5,10 , $15,20,30,45,60,120,240$ y 480 minutos post-administración. El grupo 2, constituido por seis caballos, recibió una dosis simple de ampicilina sódica de $20 \mathrm{mg} / \mathrm{kg}$, siguiendo el procedimiento indicado anteriormente.

Las muestras de sangre fueron centrifugadas a $2.500 \times$ G durante $10 \mathrm{~min}$ para obtener el suero necesario para determinar concentraciones de ampicilina mediante métodos microbiológicos (Bennet y Cols., 1969) y USP XX (1980). El microorganismo de ensayo fue el Bacilus subtilis ATCC 6633 (Arret y Cols., 1971).

Las placas de Petri, con medio 11 (BBL) conteniendo los cilindros con muestras y estandares, fueron incubadas a $370 \mathrm{C}$ durante 18 horas en cuadriplicado con el fin de medir los halos de inhibición y después de promediarlos se calcularon las rectas de regresión con los log decimales de las concentraciones del estándar versus los obtenidos. Se utilizaron rectas de regresión que presentaron coeficientes de correlación de $\overline{\mathrm{X}}=$ 0,980 . Se aplicó la fórmula: $D=A-B \log C$, donde $\mathrm{D}=$ diámetro; $\mathrm{A}=$ intercepto en $\mathrm{mm} ; \mathrm{B}=$ pendiente y $\mathrm{C}$ el log decimal de las concentraciones estudiadas.

El análisis farmacocinético se realizó con los valores de las concentraciones sanguíneas de ampicilina mediante la aplicación de un modelo de dos compartimentos abierto utilizado en otras especies, (Baggot, 1977; Ruckebusch, 1979; Zurich y Cols., 1984). Las variaciones del medicamento en la sangre en función del tiempo se explican por la ecuación:

$$
C=A \times e^{-\alpha t}+B \times e^{-\beta t}
$$

$\mathrm{C}=$ Concentración plasmática del fármaco que varía en función del tiempo; $\mathrm{t}=$ tiempo; $\mathrm{e}=$ base de logaritmo natural; $\alpha=$ constante de distribución; $\beta=$ constante de eliminación; $\mathrm{A}=$ concentración a tiempo 0 de la fase de distribución y $\mathrm{B}=$ concentración a tiempo 0 de la fase de eliminäsión.

Con el fin de obtener los valores de esta ecuación, se utilizó un programa computacional para determinar la regresión lineal entre $\operatorname{los} \log$ naturales de las concentraciones versus tiempo considerando los últimos datos. Para obtener los valores iniciales se realizó una nueva regresión de las diferencias obtenidas por el método de los

\footnotetext{
* Ampicilina Sulfato 2,5 g. Uso veterinario.
}

residuos entre las concentraciones reales $y$ teóricas (Arancibia y Cols., 1978). Los valores de los restantes parámetros farmacocinéticos fueron obtenidos mediante la aplicación de ecuaciones clásicas que aparecen en Baggot (1978), Ritschel (1980) y Cid (1982).

\section{RESULTADOS}

\section{Niveles Sangúneos de Ampicilina}

En la Fig. 1 se observan las curvas de concentraciones sanguíneas de ampicilina postadministración intravenosa de 10 y $20 \mathrm{mg} / \mathrm{kg}$ que presentan un rápido descenso inicial, desde tiempo 0 hasta $60 \mathrm{~min}$., seguido de un decremento lento entre los 60 y $360 \mathrm{~min}$. Este comportamiento bifásico se observó en ambas series de experimentos. En el cuadro 1 se muestran los valores y sus medidas de dispersión.

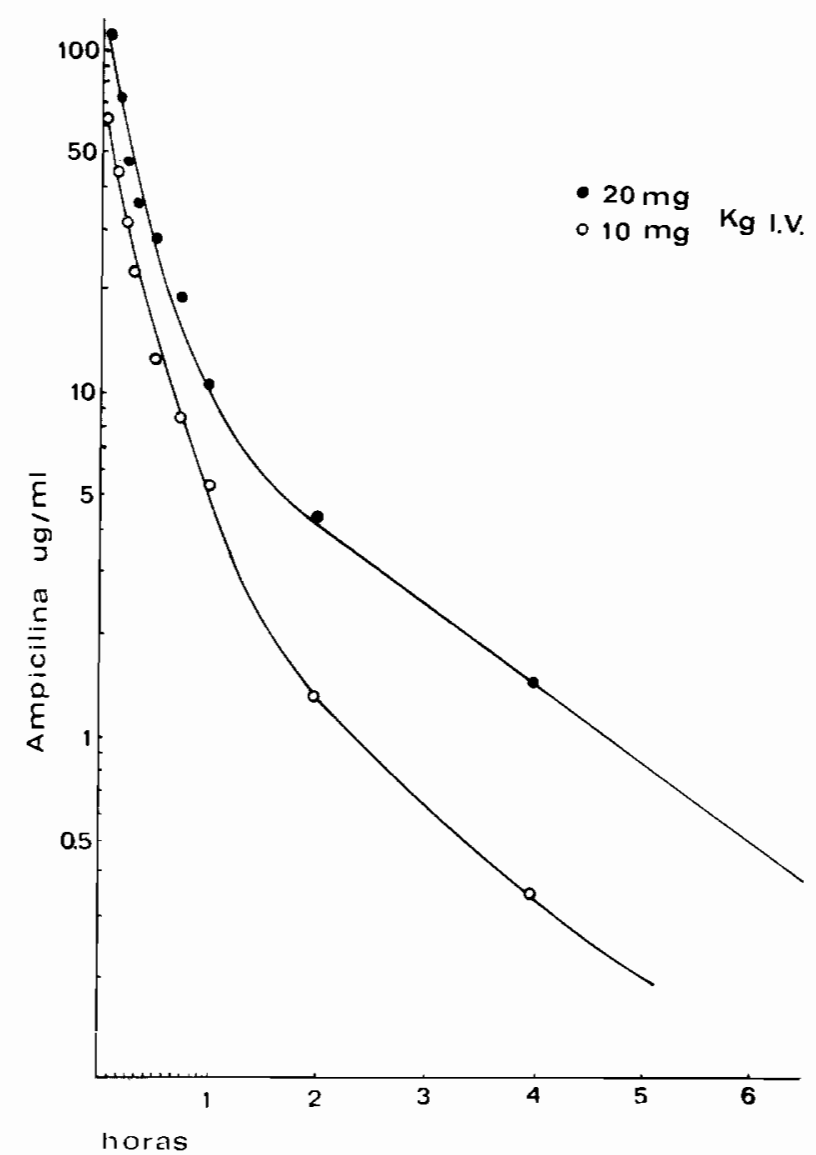

FIGURA I

Curvas de concentración observadas (símbolos) y esperadas (trazos) de 20 (๑) y 10 (o) mg/kg de Ampicilina vía venosa. 
CUADRO 1. CONCENTRACIONES SERICAS PROMEDIO DE AMPICILINA

10 Y $20 \mathrm{mg} / \mathrm{kg}$ I.V. EN EQUINOS

\begin{tabular}{|c|c|c|c|c|c|c|c|}
\hline \multicolumn{4}{|c|}{ AMPICILINA $10 \mathrm{mg} / \mathrm{kg}$} & \multicolumn{4}{|c|}{ AMPICILINA $20 \mathrm{mg} / \mathrm{kg}$} \\
\hline $\begin{array}{l}\text { TIEMPO } \\
\text { (min) }\end{array}$ & $\mathrm{N}^{\mathrm{O}}$ & $\begin{array}{c}\text { CONCENTRACION } \\
(\mu \mathrm{g} / \mathrm{m} 1)\end{array}$ & $\mathbf{S}$ & $\begin{array}{l}\text { TIEMPO } \\
(\mathrm{min})\end{array}$ & No & $\begin{array}{c}\text { CONCENTRACION } \\
(\mu \mathrm{g} / \mathrm{m} 1)\end{array}$ & $\mathbf{S}$ \\
\hline 5 & 11 & 72,182 & 19,1 & 5 & 6 & 102,09 & 28,49 \\
\hline 10 & 11 & 51,207 & 12,4 & 10 & 6 & 67,34 & 16,61 \\
\hline 15 & 11 & 35,841 & 9,59 & 15 & 6 & 48,91 & 12,10 \\
\hline 20 & 11 & 26,40 & 5,67 & 20 & 6 & 35,53 & 6,32 \\
\hline 30 & 11 & 14,180 & 4,68 & 30 & 6 & 27,67 & 5,45 \\
\hline 45 & 11 & 8,065 & 2,25 & 45 & 6 & 18,74 & 5,96 \\
\hline 60 & 11 & 5,179 & 1,60 & 60 & 6 & 9,91 & 2,67 \\
\hline 120 & 11 & 1,57 & 0,68 & 120 & 6 & 4,02 & 3,06 \\
\hline 240 & 11 & 0,525 & 0,49 & 240 & 6 & 1,52 & 2,76 \\
\hline 480 & 11 & 0,091 & 0,12 & 480 & 6 & 0,23 & 0,39 \\
\hline
\end{tabular}

2. Análisis farmacocinético mediante aplicación de un modelo abierto de dos compartimentos. La cinética de distribución y eliminación de ampicilina, en ambas dosis, se estudió reemplazando los términos de la ecuación en la forma siguiente:

$$
\begin{aligned}
& \mathrm{Cp}=82,484 \times \mathrm{e}^{-0,1438 \mathrm{t}}+11,243 \times \mathrm{e}^{-0,0137 \mathrm{t}} \text { para } 10 \mathrm{mg} / \mathrm{kg} \\
& \mathrm{Cp}=151,25 \times \mathrm{e}^{-0,1283 \mathrm{t}}+25,577 \times \mathrm{e}^{-0,0135 \mathrm{t}} \text { para } 20 \mathrm{mg} / \mathrm{kg}
\end{aligned}
$$

Con los valores se construyeron las rectas que se muestran en la Fig. 2 y que representan la velocidad con la cual ocurren los procesos cinéticos de primer orden de las fases de distribución y eliminación. Es notable el paralelismo de las fases de distribución de ambas dosis de ampicilina y que corresponde a un comportamiento cinético lineal. Los valores de $t 1 / 2$ alfa y $t / 2$ beta, que se muestran en el cuadro 2 expresan la vida media plasmática de distribución y eliminación, reflejan la rapidez del proceso. La velocidad de distribución fue 8,7 veces mayor que la de eliminación con la dosis de $10 \mathrm{mg} / \mathrm{kg}$ y de 8,48 veces superior para la dosis de $20 \mathrm{mg} / \mathrm{kg}$.

Los parámetros farmacocinéticos adicionales se presentan en los cuadros $2,3,4$, y con éstos

CUADRO 2. PARAMETROS FARMACOCINETICOS DE AMPICILINA

\begin{tabular}{|c|c|c|c|c|c|c|c|}
\hline \multirow[b]{2}{*}{ PARAMETRO } & \multicolumn{3}{|c|}{ AMPICILINA $10 \mathrm{mg} / \mathrm{kg}$} & \multicolumn{2}{|r|}{ AMPICILINA } & \multirow{2}{*}{$\begin{array}{c}20 \mathrm{mg} / \mathrm{kg} \\
\mathrm{s}\end{array}$} & \multirow[b]{2}{*}{ UNIDADES } \\
\hline & No & $\overline{\mathrm{X}}$ & $\mathrm{S}$ & No & $\overline{\mathbf{X}}$ & & \\
\hline$\beta$ & 12 & 0,0137 & 0,0047 & 6 & 0,0135 & 0,0050 & $\min -1$ \\
\hline B & 12 & 11,243 & 3,995 & 6 & 25,577 & 17,911 & $\mu \mathrm{g} / \mathrm{m} 1$ \\
\hline$\alpha$ & 12 & 0,1438 & 0,0750 & 6 & 0,1283 & 0,056 & $\min ^{-1}$ \\
\hline A & 12 & 82,484 & 99,990 & 6 & 151,25 & 54,631 & $\mu \mathrm{g} / \mathrm{m} 1$ \\
\hline $\mathrm{V}_{\mathrm{c}}$ & 12 & 0,072 & 0,038 & 6 & 0,132 & 0,052 & $1 \mathrm{t} / \mathrm{kg}$ \\
\hline $\mathrm{K}_{12}$ & 12 & 0,0468 & 0,0353 & 6 & 0,0532 & 0,0358 & $\min -1$ \\
\hline $\mathrm{K}_{10}$ & 12 & 0,0553 & 0,0439 & 6 & 0,0582 & 0,0198 & $\min ^{-1}$ \\
\hline $\mathrm{K}_{21}$ & 12 & 0,0227 & 0,0103 & 6 & 0,0304 & 0,0149 & $\min ^{-1}$ \\
\hline $\mathrm{Vt}$ & 12 & 0,144 & 0,044 & 6 & 0,186 & 0,061 & $1 \mathrm{t} / \mathrm{kg}$ \\
\hline Várea & 12 & 0,394 & 0,109 & 6 & 0,588 & 0,246 & $1 \mathrm{t} / \mathrm{kg}$ \\
\hline $\mathrm{ABC}$ & 12 & 2070,1 & 380,5 & 6 & 3234,7 & 1388,8 & $\mu \mathrm{g} \mathrm{x} \min / 1 \mathrm{t}$ \\
\hline Vss & 12 & 0,191 & 0,076 & 6 & 0,323 & 0,086 & $1 \mathrm{t} / \mathrm{kg}$ \\
\hline Vex & 12 & 1,380 & 1,331 & 6 & 1,470 & 1,067 & $1 \mathrm{t} / \mathrm{kg}$ \\
\hline $\mathrm{CL}$ & 12 & 0,00007 & 0,00002 & 6 & 0,0001 & 0,00003 & $\mathrm{~m} 1 / \mathrm{min}$ \\
\hline Т $1 / 2 \alpha$ & 12 & 6,56 & 3,73 & 6 & 6,89 & 3,71 & $\min$ \\
\hline Т $1 / 2 \beta$ & 12 & 57,37 & 21,07 & 6 & 58,48 & 20,25 & $\min$ \\
\hline
\end{tabular}
10 Y $20 \mathrm{mg}$ I.V. VALORES PROMEDIO Y SU DESVIACION

$\beta$ y $\alpha=$ Fase de Eliminación y de Distribución; B y A $=$ Concentraciones extrapoladas, tiempo $0 ; \mathrm{Vc}=$ Volumen distribución central; $\mathrm{Vt}=$ Volumen distribución tejidos; Varea $=$ Volumen del área; Vex $=$ Volumen extrapolado; Vss $=$ Volumen de pseudoequilibrio ("Steady State"); K10 = Constante de eliminación; K12 y K21 = Constantes de transferencia intercompartimentos; $\mathrm{ABC}=$ Area bajo la curva; $\mathrm{C} 1=$ Depuración de la sustancia en el organismo; $\mathrm{T} 1 / 2=\mathrm{Vida}$ media de distribución; $T 1 / 2 \beta=$ Vída media de eliminación. 


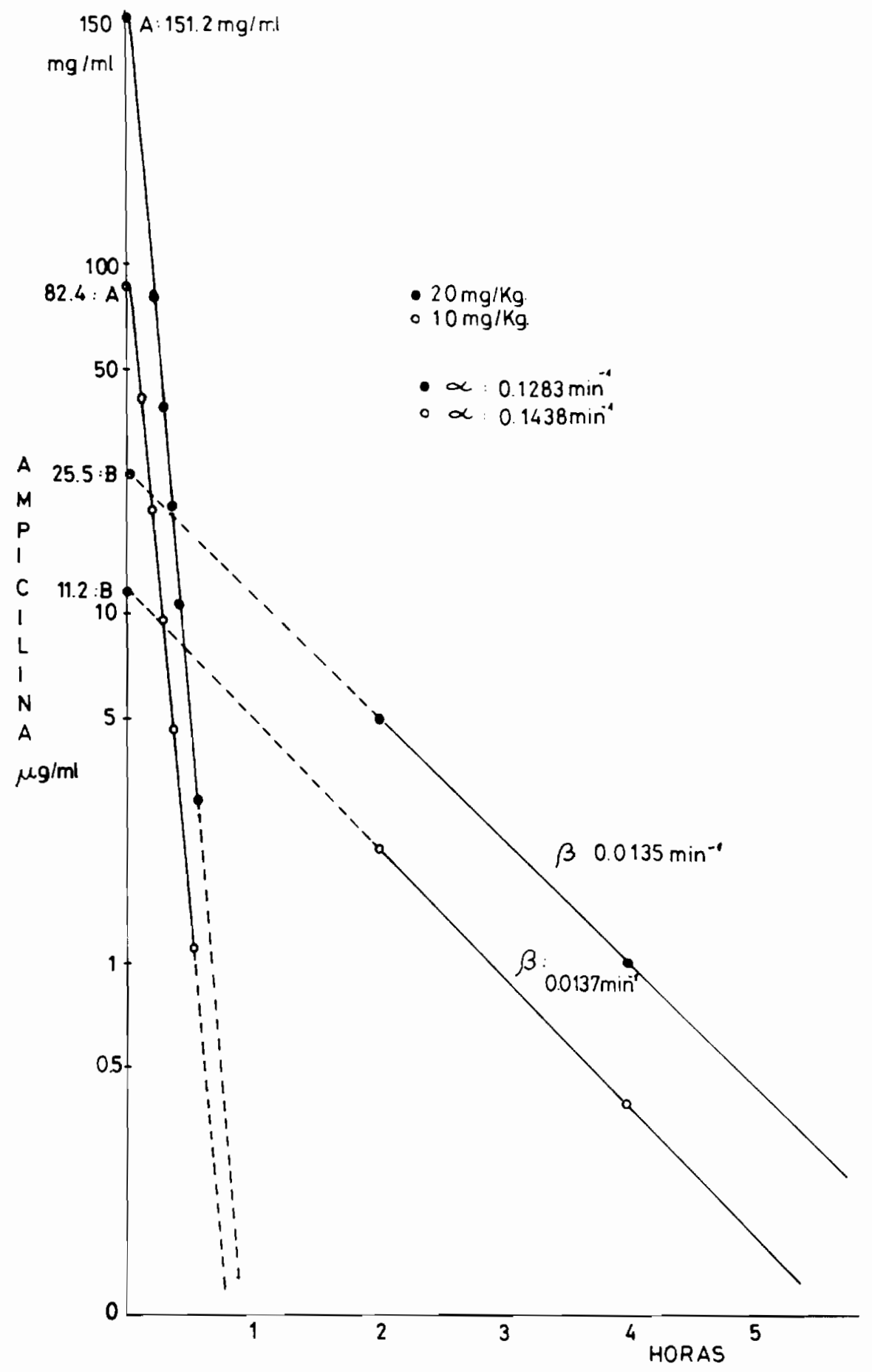

FIGURA 2

Trazado semilogarítmico de las concentraciones de ampicilina versus tiempo, que muestra la cinética de distribución (alfa) y de eliminación (beta) en dosis de 10 (o) y $20(\bullet) \mathrm{mg} / \mathrm{kg}$.

$A=$ Concentracion en el tiempo cero de la fase de distribución $B=$ Concentración en el tiempo cero de la fase de eliminación $\alpha=$ Concentración de distribución

$\beta=$ Constante de eliminación 


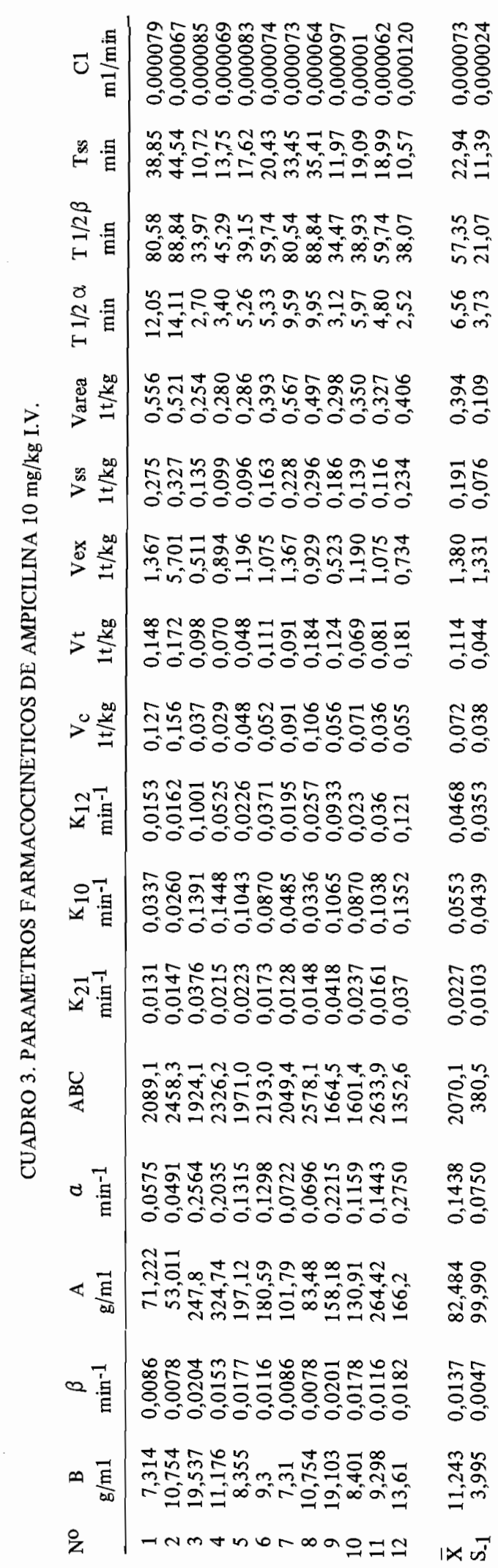

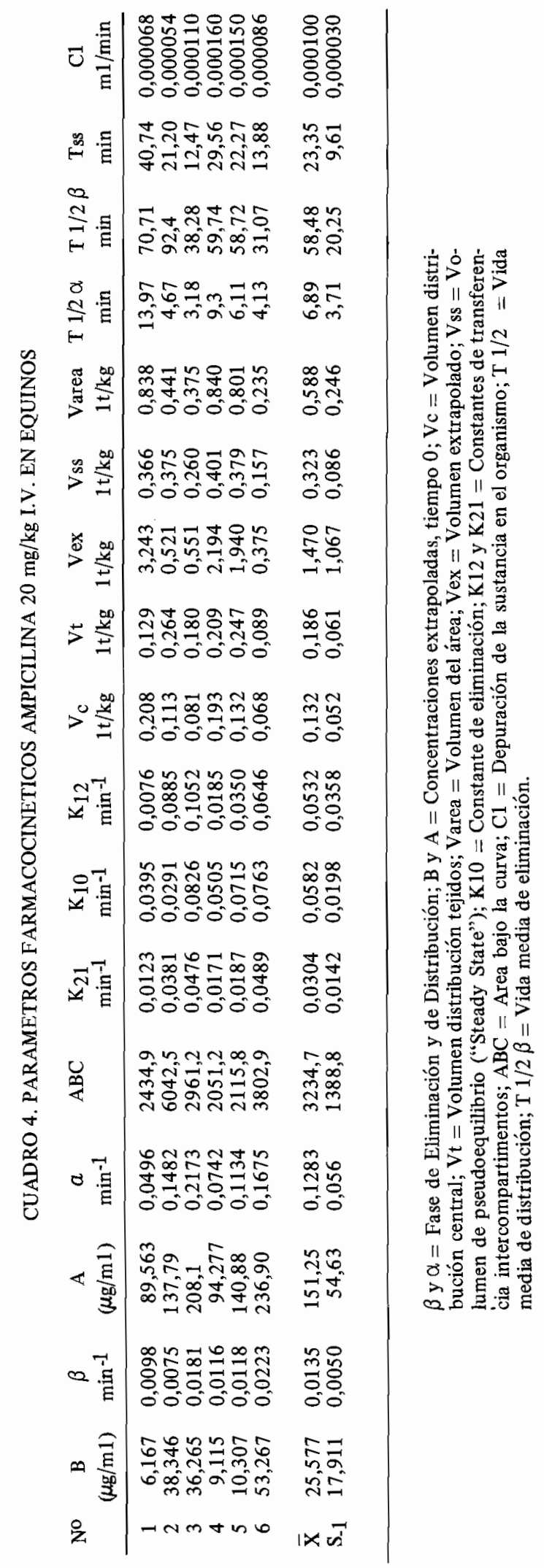


fue posible esquematizar un modelo de dos compartimentos, tal cual se puede observar en la Fig. 3. El volumen de distribución (Vd) de ampicilina en el compartimento periférico fue superior al determinado para el compartimento central. Un simple cálculo de la razón permite establecer que el $\mathrm{Vd}$ periférico fue 1,5 y 1,4 veces superior al mismo parámetro del compartimento central con 10 y $20 \mathrm{mg} / \mathrm{kg}$ respectivamente. Estos hechos se comprenden mejor observando los valores de las constantes de transferencia, $\mathrm{k}_{12}$ $\mathrm{y}_{21}$, y que reflejan el mayor paso del antibiótico desde la sangre hacia los tejidos menos irrigados. La constante de eliminación, $\mathrm{k}_{10}$, en ambos casos, es de mayor magnitud que las de transferencia.
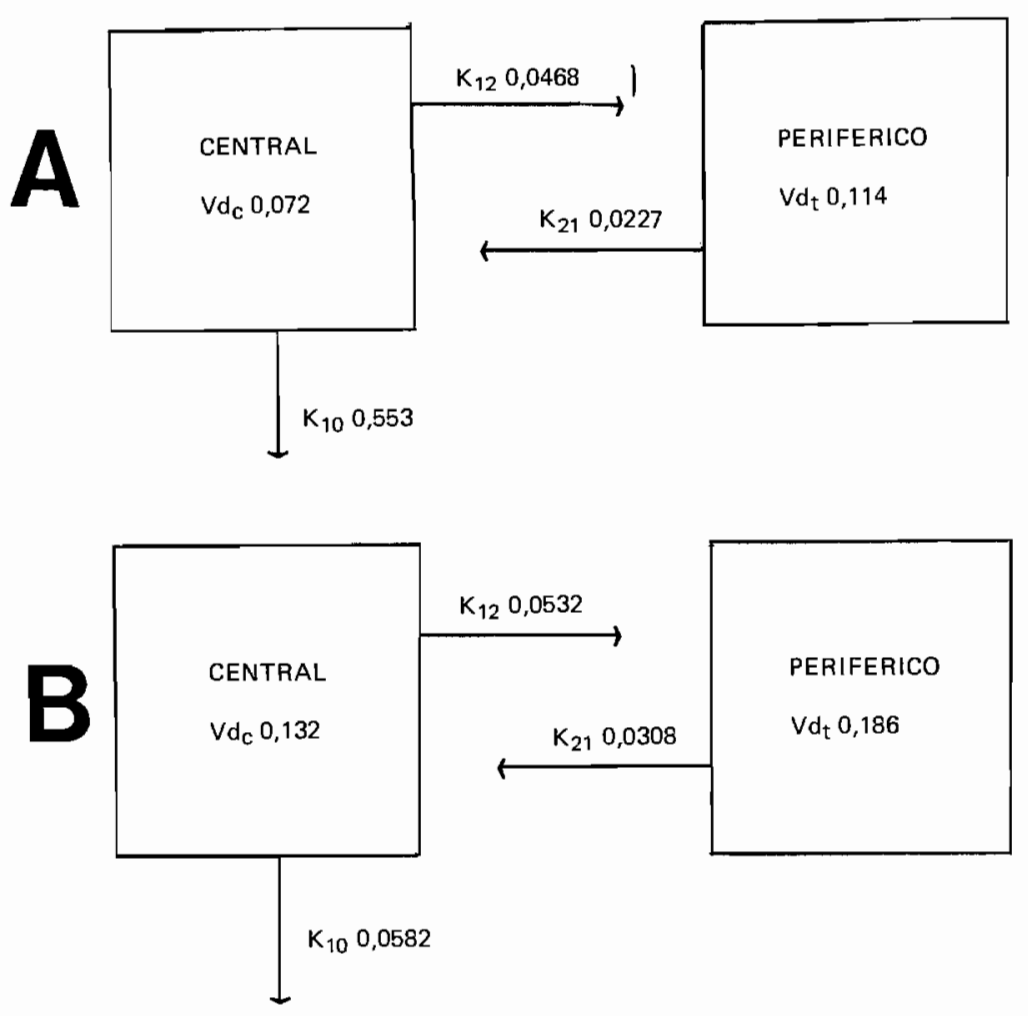

FIGURA 3

Esquema de modelo de dos compartimentos

$A=10 \mathrm{mg} / \mathrm{kg} \quad B=20 \mathrm{mg} / \mathrm{kg}$

$\mathrm{Vdc}=$ volumen de distribución del compartimento central

Vdt $=$ volumen de distribución del compartimento periférico

K12 = constante de transferencia desde $C$. central hacia $C$. periférico

$\mathbf{K 2 1}=$ constante de transferencia desde $\mathrm{C}$. periférico hacia $\mathrm{C}$. central

K10 = constante de eliminación desde el compartimento central

Las variaciones de las cantidades de ampicilina en ambos compartimentos en función del tiempo se pueden observar en la Fig. 4 y permiten confirmar la disposición de la ampicilina en el equino a través de un modelo bicompar. timental $\mathrm{y}$, además, permite establecer la temprana saturación del sistema, esto es, el momento en que se alcanza igual distribución de la droga en ambos compartimentos y que co- rresponde al estado de seudoequilibrio. Este estado se alcanzo, en tiempo breve siendo de $22,94 \mathrm{~min}$ y $23,35 \mathrm{~min}$ para 10 y $20 \mathrm{mg} / \mathrm{kg}$ respectivamente.

Finalmente, los valores de "clearance" permitieron apreciar, en ambas series de experimentos, un fenómeno de depuración del Vd con un comportamiento cinético similar, siendo superior el de $20 \mathrm{mg} / \mathrm{kg}$ en relación a $10 \mathrm{mg} / \mathrm{kg}$. 
DISTRIBUCION AMPICILINA EN EQUINOS CON 10 $\mathrm{mg} / \mathrm{kg}$ VIA

iNTRAVENOSA EN C. CENTRAL Y C. PERIfERICO
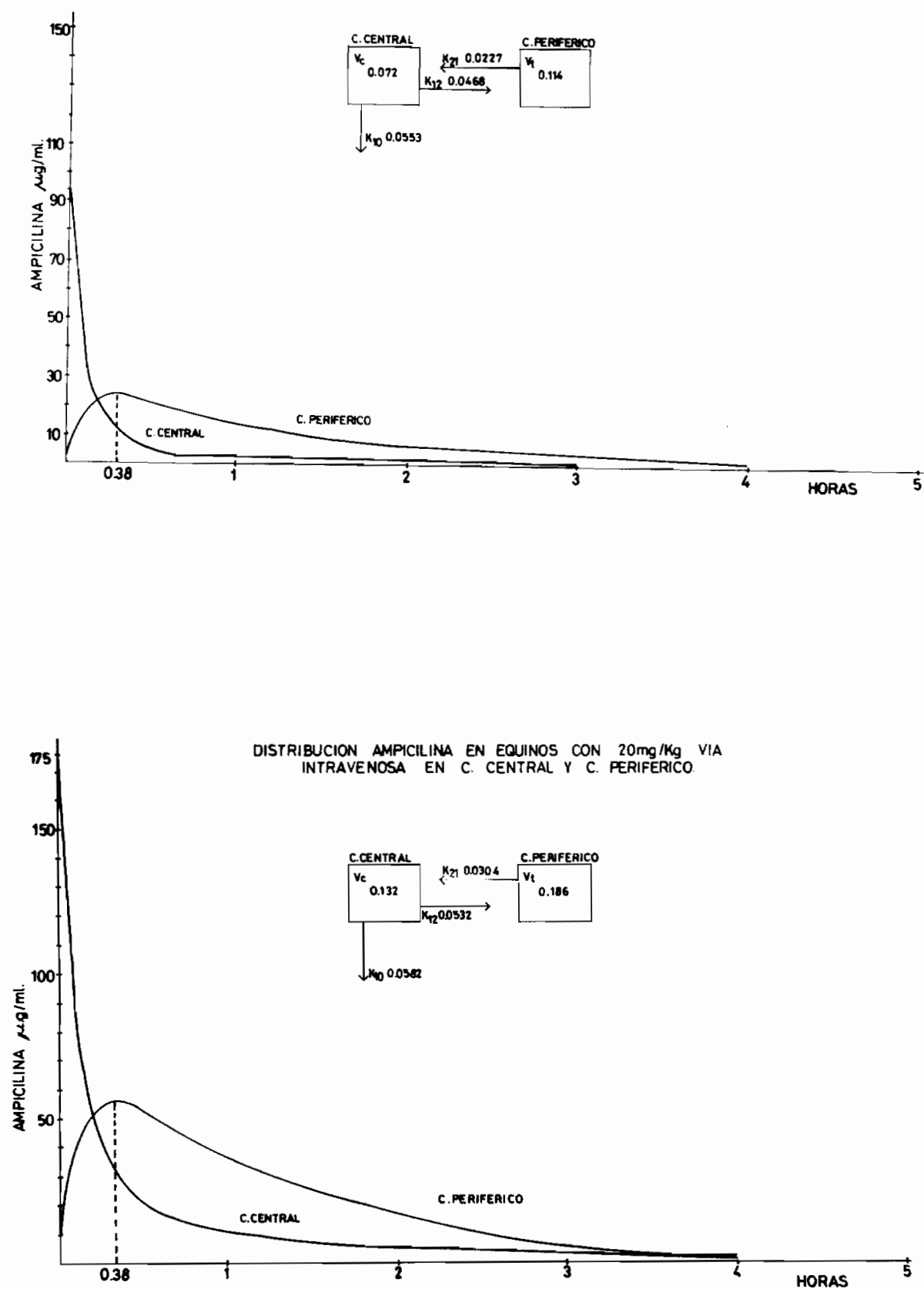

FIGURA 4

Variaciones de las cantidades de ampicilina en el tiempo en ambos compartimentos con $10 \mathrm{mg} / \mathrm{kg}$ (Superior) y $20 \mathrm{mg} / \mathrm{kg}$ (Inferior). Linea de puntos representa el tiempo en el cual se alcanza el seudoequilibrio del sistema. 


\section{DISCUSION}

Nuestros resultados permiten establecer que los procesos de distribución y eliminación fueron coincidentes con los descritos por Dürr (1976) en equinos e independientes de la dosis administrada. Asimismo, ambas fases y con ambas dosis se disponen según una cinética de primer orden ya que son muy similares entre si $\beta ; k_{10} ; \mathrm{t} 1 / 2 \alpha ; \mathrm{t} 1 / 2 \beta$; Tss.

Interesante, a nuestro juicio, es la similar rapidez de la distribución del antibiótico y apreciado por los valores de vida media plasmática, $\mathrm{t} 1 / 2$ alfa, que fluctuaron entre $6,56 \mathrm{y}$ 6,89 minutos para 10 y $20 \mathrm{mg} / \mathrm{kg}$ de ampicilina. La eliminación, en ambos casos, fue más lenta y no existe relación entre la mayor dosis $\mathrm{y}$ menor valor de $\mathrm{t} 1 / 2$ beta, que puede ser explicada, tal vez, por la mayor cantidad de droga en el organismo.

La adopción de un modelo de dos compartimentos se ajusta a nuestros resultados y coincide con la disposición compartimental de ampicilina en otras especies (Ruckebusch, 1979; Zurich y Cols., 1984). En efecto, los valores de las constantes de distribución, $\mathrm{k}_{12} \mathrm{y} \mathrm{k}_{21}$, muestran claramente la velocidad y extensión del paso de ampicilina entre ambos compartimentos. Esta mayor difusión desde sangre explica el mayor volumen de distribución en el compartimento periférico, hecho que permite suponer que concentraciones antimicrobianas de este antibiótico se pueden alcanzar no sólo en sangre sino, además, en tejidos de menor perfusión. Al respecto, parece importante mencionar a Ritschel (1980) quien, basado en evidencias experimentales postula que el volumen de distribución cuando alcanza entre 35 y $48 \%$ del peso corporal, la droga se distribuye en el tejido extra e intercelular; en nuestro caso este hecho ocurre sólo para 20 $\mathrm{mg} / \mathrm{kg}$ alcanzando volúmenes de distribución de $32,3 \%$. En cambio con $10 \mathrm{mg} / \mathrm{kg}$ fue de $19,1 \%$ expresado como porcentaje de peso corporal hecho que puede tener proyección terapéutica según la localización de bacterias patógenas sensibles.

Esta rápida difusión de ampicilina ha sido en parte explicada, por la escasa unión del antibiótico a las proteínas plasmáticas del equino (Dürr, 1976) y, además, por la lipofilia de esta sustancia (Ziv y Cols., 1973; Ruckebusch, 1979). Ambas condiciones son esenciales para los fenómenos de difusión a través de membranas biológicas. Nuestros experimentos no permiten obtener conclusiones al respecto.

El modelo compartimental y los parámetros farmacocinéticos estudiados permiten atribuir a la ampicilina importancia terapéutica relevante en infecciones localizadas, de preferencia, en tejidos extravasculares.

\section{RESUMEN}

La cinética de distribución y eliminación de ampicilina sódica en equinos sanos, se estudia a través de las concentraciones sanguíneas del antibiótico determinadas post administración intravenosa de 10 y $20 \mathrm{mg} / \mathrm{kg}$.

Las curvas de concentraciones sanguíneas de ampicilina con sus correspondientes fases de distribución y eliminación en el tiempo, permiten la aplicación de una ecuación biexponencial que caracteriza la disposición del fármaco mediante un modelo abierto de dos compartimentos con volumen de distribución mayores en el compartimento periférico en relación al central. Las constantes de transferencia intercompartimentales $\left(\mathrm{k}_{12}\right.$ y $\left.\mathrm{k}_{21}\right)$, reflejan esta distribución. La rápida distribución y consecuente difusión desde sangre hacia tejidos, puede ser atribuida a una baja unión a proteínas sanguineas o a las características lipofílicas del antibiótico.

\section{AGRADECIMIENTOS}

Los autores agradecen al Prof. Edison Cid por su valiosa ayuda a los cálculos farmacocinéticos; Profesores Rubén Maldonado y Carlos Porter por las facilidades otorgadas para realizar el trabajo.

\section{REFERENCIAS}

ARANCIBIA, O.A; O. PINTO; I. MORALES. Empleo de la computación en la determinación de parámetros farmacocinéticos en un modelo de dos compartimentos. Revista CECOM (Facultad de Medicina Norte, Universidad de Chile). No $4: 17-32,1978$.

ARRET, B.; D. JHONSON; A. KIRSCHBAUM. Outline of detail for microbiological assays of antibiotics. J. Pharm. Sci. $60: 1689-1694,1971$.

BAGGOT, J.D. Principles of drug disposition in domestic animals: The basis of veterinary clinical pharmacology Phil, Saunders. 1977

BAGGOT, JD. Some aspects of clinical pharmacokinetics in veterinary medicine. J. Vet. Pharmacol. 1:5$18,1978$.

BENNET, J.V ; J.L. BRODIE; E.J. BENNER; WM KIRBY. M. Simplified accurate method for antibiotic assay of clinical specimens. Appl. Microbiol. 14: 170-177, 1969.

BOOTH, N.H.; L.E. MacDONALD. Veterinary Pharmacology and Therapeutics. 5ht ed. Ames, Iowa State University Press, 1982

BRANDER, C.G.; D.M. PUGH. Veterinary applied 
pharmacology and therapeutics. 3rd ed. Phil, Lea and Febiger, 1982.

CID, E. In troducción a la farmacocinética. Washington, DC, OEA, 1982 (monografía $\mathrm{N}^{\circ} 25$, serie de Biología).

DURR, A., A comparation of the pharmacokinetics of penicillin $G$ and ampicillin in the horse. Res. Vet. Sci., 20:24-29, 1976.

GALTIER, P.; J.L. CHARPENEAU. Pharmacokinetic of ampicillin in pigs. J. Vet. Pharmacol. Therap. 2:181-186, 1979.

MERCER, M.D.; R.C. GARG; JD. POWER; T.E.POWER. bioavailability and pharmacokinetics of several dosage forms of ampicillin in cats. Am. J. Vet. Res. 38:1353-1359, 1977.

RITSCHEL, W.A $\rightarrow$ Handbook of basic pharmacokinetics. 2nd. ed. Hamilton Drug Intelligence, 1980.
RUCKEBUSCH, 1. Biodisponibilité et medicamenteuse. Cah. Méd. Vét. 98:9-22, 1979.

TOBIN, Th. Drugs and the performance horse. Charles C. Tomas Springfield, III., 1981.

U.S. PHARMACOPEIA, U.S.P. XX. Biological test and assays. 81. Antibiotics microbial assays. National Formulary, pp. 882-888, 1980.

ZIV, G.; J. SHANI; E_G. SULMAN. Pharmacokineties evaluations of penicillin and cephalosporin derivatives in serum and milk of lactating cows and ewes. Am. J.Vet. Res. 34:1561-1565, 1973.

ZURICH, L.; M. VILLALOBOS. Penicilinas en Medicina Veterinaria. Monografías de Medicina Veterinaria. 1: 17-34, 1979.

ZURICH, L-; M.T. CALDERON; M. BARAONA; H YAIKIN. Estudio farmacocinético de ampicilina en gallinas. Arch. Med. Vet. 16:15-20, 1984.

Aceptado para su publicación. 12 Diciembre 1985. 